\title{
Research on aero engines based on green energy saving
}

\author{
Xu Xiaoning ${ }^{1, a}$ \\ ${ }^{1}$ School of Aeronautics, Chongqing Jiaotong University, Chongqing, China
}

\begin{abstract}
As a bridge between the economy and society, air transportation plays an important role, and the aircraft engine, which is the "heart" of the aircraft, is the key to achieve all this. However, in recent years, the particulate matter emission and carbon dioxide greenhouse effect of aircraft have brought serious pollution to the world and are of great concern. Therefore, this paper will be based on the concepts of low carbon, green, energy saving, environmental protection and safety, as well as the social development requirements of carbon balance. By studying the pollution sources and elimination methods of aviation engines, further analyzing the development process of green aviation in China and the experience and inspiration of developing green aviation in Europe, the paper aims to propose innovative development ideas in the field of aviation power in order to better serve economic development and social progress.
\end{abstract}

\section{Introduction}

An aircraft engine is a highly complex and sophisticated thermal machinery, which provides the power required for the aircraft to fly. As the heart of the aircraft, it is known as the "flower of industry", which directly affects the performance, reliability and economy of the aircraft, and is an important embodiment of a country's technological, industrial and national defense strength. It is of great significance to promote national economic development and enhance national core competitiveness. It is because of the important strategic position of the aero-engine and its role in promoting national economic and scientific development that China attaches great importance to its development and has implemented a series of national major science and technology projects, which have strongly promoted the development of this field. Since the reform and opening up, China has made great progress in the production and development of advanced military engines, the development of civil engines for the domestic large passenger aircraft C919, and the development of advanced air and space power [1].

Power is the most dynamic and revolutionary factor in human society. The invention of the steam engine opened the era of mechanical power, dramatically increased labor productivity, and triggered the first industrial revolution. The same is true in the field of aviation: the invention of each new generation of engines has driven the introduction of a new generation of aircraft. And with the rapid development of civil aviation transportation industry and people's increasing awareness of environmental protection, the problem of aviation emission pollution has also received wide attention. In the long time of exploring flight, human beings began to pursue clean and green aviation. Nowadays, energy saving and environmental protection has become one of the important goals of modern civil aviation engine development, and how to better integrate the green development concept into aviation engine technology research has long been a global issue.

\section{Green transformation of aero engines}

\subsection{Sources of engine pollution}

The main pollutants of civil aviation engines are carbon monoxide (CO), nitrogen oxides (NOx), incomplete combustion hydrocarbons (UHC), etc. Among them, NOx has the most serious impact on the ecological environment, which will destroy the ozone layer and cause pollution such as acid rain, acid fog and haze. The combustion chamber is the main source of pollutant emissions from aero engines, and the harsh environment of high temperature and pressure in the combustion chamber has become a breeding ground for NOx instead [2]. With the progress of engine technology, the combustion chamber temperature is getting higher and higher, and when the gas temperature exceeds $1600^{\circ} \mathrm{C}$, the generation of NOx increases significantly. At the same time, the propulsion system, the turbulence of hot air discharged from the turbojet, and the rotor rotation of the turbofan all emit a lot of noise, causing noise pollution to the residents around the airport.

\subsection{Measures to reduce emissions}

In the combustion chamber, there is a correspondence between temperature, oil to gas ratio and NOx production, so the emission can be reduced by adjusting the oil to gas ratio. When there is less fuel than air, the combustion process is called oil-poor combustion, and when there is excess fuel, it is called oil-rich combustion. There are three main technologies in the research of low-emission

\footnotetext{
a Corresponding author: xu2423390870@163.com
} 
combustion technology: lean oil premixed preevaporative combustion (LPP) for lean oil combustion, lean oil direct mixed combustion (LDM) and rich oil combustion-rapid quenching-lean oil combustion (RQL) for rich oil combustion [3].

LPP: The fuel is completely evaporated and mixed with air evenly into the combustion zone, and the combustion zone is lean, the leaner the fuel, the lower the temperature, the less NOx emission.

LDM: The fuel is injected directly or mixed with air to a certain extent beforehand and then injected into the combustion zone for combustion, making the combustion zone in an oil-poor state.

RQL: Firstly, oil-rich combustion is carried out, and then a large amount of air is injected into the combustion zone, and the air is rapidly mixed with the products in the combustion zone to enter the oil-poor combustion state, thus reducing NOx generation.

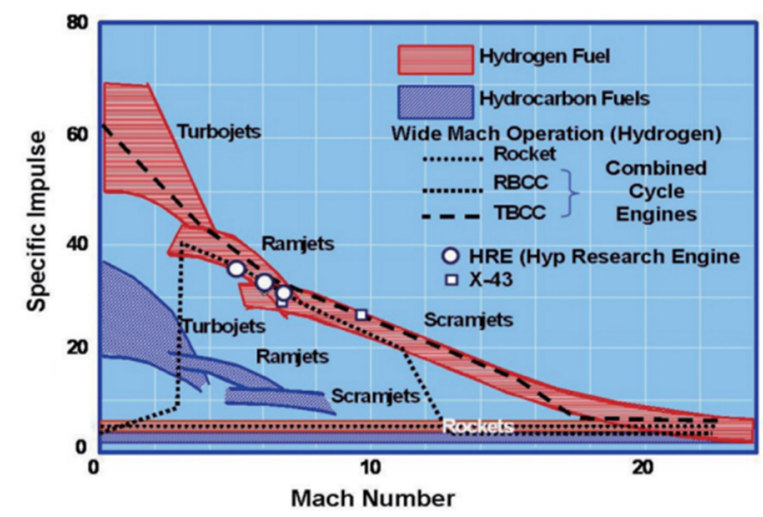

Figure 1. Variation of specific impulse with flight Ma for each engine type (Image from the web)

\subsection{China's green aviation development process}

In recent years, China has gradually promoted the research of low-emission combustion technology, from basic simulation to experimental research to product develop-ment, and the domestic low-emission combustion chamber technology has gradually matured, mainly based on oil-poor combustion technology, supplemented by oil-rich combustion technology. At present, many universities and research institutes are actively carrying out research on key technologies of lowemission combustion chamber. Beijing University of Aeronautics and Astronautics has obtained a number of patents on low-emission combustion chamber, and the basic research on low-emission combustion chamber has been deepened, and a low-emission stirred cyclone combustion chamber has been developed. CAF Turbine Institute has combined two kinds of oil-poor combustion technologies, LPP and LDM, independently designed part of the premixed pre-evaporation low-emission combustion chamber, and obtained a number of patents; CAF Power Institute has carried out research on lowemission combustion technology for the needs of gas turbines, and has also made important breakthroughs.

\section{The experience and inspiration of developing green aviation in Europe}

\subsection{European Green Aviation Disruptive Techno- logies}

\subsubsection{Hybrid regional aircraft}

In terms of key technologies to reduce greenhouse gas emissions, there are currently two architectures of power systems for such hybrid aircraft designs, namely hybrid electric systems and turbine electrical systems. This hybrid aircraft requires new designs and solutions for completely new propulsion systems. First, the new system needs to be aerodynamic design and characteristics, aerodynamic toughness analysis, flight control and flight management systems for safety verification; second, the need to develop a new design system that can predict aircraft design parameters and performance, and can use the "digital twin" and other virtual design technology to carry out integration and verification of the aircraft; third, to explore new configurations and expand the current hybrid aircraft design of two architectures, namely, hybrid electric and turbine electric systems [4]. Third, to explore new configu-reations and extend their performance range; fourth, to redesign the airframe and study advanced assembly and manufacturing solutions to accommodate the new capabi-lities of the hybrid system and to effectively control costs; fifth, to minimize carbon emissions.

\subsubsection{Super-efficient short-range aircraft}

The aircraft will utilize disruptive airframe technologies and an ultra-efficient propulsion system using hydrogen as an indirect fuel to increase energy use efficiency by 30 percent. To develop the disruptive ultra-efficient shortand medium-range aircraft, the EU will focus on four key technologies: high-efficiency airframe, ultra-efficient propulsion system development and integration, green flight operation system, and green sustainable life cycle technology. In the area of high-efficiency airframe development, the EU will evaluate new materials, system architectures and design concepts, and will use the $\mathrm{X}$ Plane project as the basis for advancing the technology development of high-performance wings and conducting ground demonstrations [5]. In the area of ultra-efficient propulsion system development and integration, the combination of a thermal propulsion system and a zerocarbon power system will be the primary power base for a new short- and medium-range aircraft. The design goal of the new power system is to reduce fuel consumption by $20 \%$. To develop the new power system, the EU will develop smarter engines, simplify system design and use new clean emission technologies.

\subsubsection{Hydrogen aircraft}

As a clean fuel, hydrogen fuel can significantly reduce the level of carbon emissions during and throughout the life 
cycle of aviation flight, providing an important contribution to sustainable environmental cleanup. The current hydrogen power system technology does not yet meet the needs of aviation flight and requires significant research work. The EU will promote the technical exploration of hydrogen power system applications in four areas: environmental potential assessment, propulsion system development, aircraft integration and safety certification [6]. In terms of environmental potential assessment, the environmental impact of hydrogen-powered aircraft needs to be fully assessed as water vapor from hydrogen combustion emits nitrogen oxides. In terms of propulsion system development, hydrogen fuel storage, distribution and combustion systems will be the key to developing hydrogen-powered energy systems.

\subsection{What Europe's green disruptive aviation technology tells us}

Development of green aviation, leading the global aviation industry change: Currently, civil aviation technology is developing in the direction of green, efficient, low-cost and intelligent. Europe has set "energy saving and emission reduction" as the main goal of future civil aviation development, and is using the "Clean Sky" program to promote specific technical projects. As a result, large-scale resources in the field of civil aviation will be invested in the research, design and development of environmentally friendly aircraft in the future, which will directly drive the progress and change of related technologies. With the low-carbon goal in mind, green aviation technology, represented by electricity and hydrogen fuel, will become the future direction of aviation technology for some time, triggering a change in the aviation industry.

Strengthen cooperation and reduce risk: The aviation industry is characterized by high investment, high risk, long cycle time and high technological threshold. It is difficult for a single country or private enterprise to bear the risk of huge capital investment and technology R\&D failure alone. Therefore, the EU has joined hands with multiple parties to develop green disruptive technologies, effectively reducing the risk of technological innovation and significantly increasing the likelihood of successful technology development. In addition, Europe's partnership to develop new aviation technologies is conducive to promoting the development of European industries such as electricity and hydrogen energy, seizing the high ground in the development of new technologies for civil aircraft, forming a community of interests and seizing the right to speak in the future rule-making in aviation.

Development of intelligent manufacturing: At present, domestic aero-engine blade repair is mainly based on manual operations, automation, integration degree is low. The development of blade intelligent remanufacturing factory will improve the quality of blade remanufacturing, shorten the maintenance cycle, meet the aero-engine maintenance needs, and effectively enhance China's aeroengine independent maintenance guarantee ability. For the current aero-engine blade remanufacturing intelligence level is low, the existing aero-engine blade remanufacturing process flow, visual management, quality control and other aspects of improvement, equipped with safe and controllable core intelligent manufacturing equipment and software, the establishment of blade intelligent remanufacturing parameters and quality control database, the blade remanufacturing to achieve intelligent planning scheduling, intelligent quality management, intelligent decision support, intelligent Resource manage-ment. Using digital twin, cloud platform and cloud computing and other technologies, build a private cloud platform to realize the sharing of blade information records before remanufacturing, process parameter information records during remanufacturing, and inspection informa-tion records after remanufacturing, and record to single blade to realize the intelligent management of single blade whole life cycle.

\begin{tabular}{ccc}
\hline$M a$ & $T_{1} / \mathrm{K}$ & $T_{2} / \mathrm{K}$ \\
\hline 1.0 & 260 & 542 \\
2.0 & 390 & 812 \\
3.0 & 607 & 1264 \\
4.0 & 910 & 1895 \\
5.0 & 1315 & 2707 \\
\hline
\end{tabular}

Figure 2. Variation of $\mathrm{T} 1$ and $\mathrm{T} 2$ with $\mathrm{Ma}$

Measures to implement a reasonable division of labor between industry, academia, research and use but also close cooperation: the aero-engine is a multidisciplinary intersection of high-end complex system, the basic element to determine its quality is the core technology. High-end products are characterized by core technology stacking. The core technology is based on scientific knowledge, while basic research is the basic way to obtain scientific knowledge and master the core technology. Mastering core technology is a long-term, complex and arduous task. Western countries for decades, invested a lot of human, material and financial resources, the construction of experimental equipment, through basic research, access to a large number of experimental data, built a systematic and complete database, to master the core technology, so basic research is the foundation of the modern Western engine industry.

Establishing specialized institutions to create basic research talents and cultivate professional technologies: attaching importance to basic research and mastering core technologies requires organizational assurance. Therefore, through a series of national programs, we should closely integrate with other scientific research institutions and research universities to acquire scientific knowledge, master core key technologies, and provide scientific and technological support for model development. The establishment of dedicated scientific research institutions is a powerful organizational measure, which is not only conducive to focusing efforts on mastering core technologies, but also to cultivating a team of talents specializing in basic research. 


\section{Equations and mathematics}

\subsection{Analysis of innovation results}

\subsubsection{Hybrid electric propulsion can further improve fuel efficiency}

The current best performing turbofan engine can only use $40 \%$ of the potential energy of the fuel; and the new generation turbofan engine being developed with variable cycle technology can only use $55 \%$ to $70 \%$ of the fuel energy. Hybrid electric propulsion technology is a new type of propulsion technology in which electricity is generated by conventional gas turbine engines to provide power to electric motors distributed on the wings or fuselage, and the electric motors drive the fans to provide most or all of the thrust (gas turbine engines can partially provide or not provide thrust). The technology is equivalent to a significant increase in the gas turbine engine's culvert ratio, and its biggest advantage is to greatly reduce the propulsion system's fuel consumption and various pollution emissions. Boeing and GE, as well as the European Airbus Group, Siemens in Germany and Rollo in the United Kingdom, have conducted research on hybrid electric propulsion technology with government support.

\subsubsection{Typical hybrid electric propulsion system}

Boeing explored a distributed hybrid electric propulsion system power solution under the Sugar program. The key feature of this solution is that one or more turboshaft engines drive a generator (set) to generate electricity, and the generated electricity is fed to separate fan/motor assemblies (and onboard subsystems) to drive multiple distributed upper, lower or internal wing fans. In addition, Boeing has partnered with GE to explore a range of hybrid electric propulsion systems, such as the eFan propulsion system with batteries, the Fan propulsion system with a fuel cell/gas turbine hybrid, and the hFan propulsion system with a battery/gas turbine hybrid. A major advantage of distributed hybrid electric propulsion systems is their ability to be integrated into the airframe structure to optimize the flow field around the airframe. A distributed fan placed at the rear of the wing draws in the boundary layer at the back of the wing and accelerates it, thereby increasing the lift-to-drag ratio of the wing, reducing the weight of the aircraft, reducing the required thrust, and contributing to lower fuel consumption and pollution.



Figure 3. High-capacity-ratio engines

\subsection{Typical Case Study}

The CFM56 engine is a technological breakthrough that outperforms the most advanced engines of its time by $20 \%$ in terms of fuel consumption, performance and pollutant emissions. The CFM56 engine is followed by its successor, the new LEAP engine, which is the fastest growing engine in the history of commercial aviation, offering high performance, economy and environmental friendliness. Compared to existing engines, it can reduce fuel consumption and $\mathrm{CO} 2$ emissions by 15 percent, reduce nitrogen oxide (NOx) emissions by 50 percent compared to $\mathrm{CAEP} / 6$ standards, and significantly reduce ground noise. The LEAP engine is available in three versions, chosen by the world's top three aircraft manufacturers.

\section{Conclusion}

Currently, the global aviation industry is shifting from incremental reforms based on reducing carbon emissions by improving fuel efficiency to revolutionary changes in the direction of developing new low-carbon propulsion technologies and new fuels, with the main goal of change being to fundamentally address low-carbon emissions. Among them, sustainable aviation fuel (SAF), new hybrid propulsion technology, hydrogen turbine and hydrogen fuel cell electric technology, have become the most representative disruptive technologies. Therefore, while applying the world's advanced technologies, it is necessary to continuously increase innovation and promote technology iteration to meet the future development requirements in the field of low-carbon aviation, which in turn will enable economic development and social progress to new heights.

\section{References}

1. Liu Z. (2020) The green road of aviation industry. Big Aircraft, 7: 50-55.

2. Yan C. (2013) Green power: open rotor aero engine. Aviation Science and Technology, 1:6-12.

3. Gu M. (2012) The future of engines based on helping green aviation--Interview with Pratt \& Whitney vice president. China Civil Aviation, 11: 13-15.

4. Jeffrey M, Eric K, David Y. (2009) The future of green aviation industry. China Civil Aviation, 4: 2627.

5. Cheng L. (2008) Green maintenance as a contribution to environmental protection. International Aviat-ion, 3: 38-40.

6. Liang C. (2005) Green civil aviation engine key technology. Aviation Science and Technol-ogy, 6: 14-16. 